\title{
BAKHTIN E LITERATURA BRASILEIRA ABORDANDO A OBRA DE MURILO MENDES ${ }^{1}$
}

http://dx.doi.org/10.11606/issn.2237-1184.v0i26p167-172

\section{Boris Schnaiderman}

Numa comunicação ao XIX Congresso Internacional da FILLM, realizado em Brasília em agosto de 1993, apresentei, em linhas gerais, uma abordagem panorâmica sobre a recepção de Bakhtin no Brasil. ${ }^{2}$ Em várias outras ocasiões, tratei das possibilidades de um estudo bakhtiniano de autores brasileiros, que ajude a esclarecer determinados aspectos. Agora, vou tratar do mesmo tema em relação a Murilo Mendes.

Logo de início, surge um paradoxo. Em vários escritos de Bakhtin, mas sobretudo em "A palavra no romance" (ou "O discurso no romance", ambas as traduções são possíveis), aparece a afirmação de que o dialogismo funciona plenamente no romance, mas não no teatro nem na poesia. Durante muitos anos, esta afirmação bakhtiniana foi para mim verdadeira "pedra no caminho", um estorvo em minha aceitação das concepções desse teórico russo. Pois, como conciliá-la com sua afirmação de que "toda a vida da linguagem, seja qual for o seu campo de emprego (a linguagem cotidiana, a prática, a científica, a literária etc.), está impregnada de relações dialógicas"?3 Já expressei esta minha perplexidade no livro Turbilhão e semente, mas ali também escrevi: "Estranho e multiforme Bakhtin! Depois de explorar exaustivamente um conceito, ele o abandona para trilhar outros caminhos, lançar-se em novas explorações". ${ }^{4}$ Ao mesmo tempo, de um trabalho para outro, sempre aparecia em sua obra aquela afirmação sobre monológico e poesia. Nesse pensador do literário e da cultura,

\footnotetext{
${ }^{1}$ Discurso de Boris no $5^{\circ}$ Congresso da ABRALIC, 1997. Texto disponibilizado como ensaio em Cânones e Contextos; Anais; Rio de Janeiro: Faculdade de Letras UFRJ, 1997.

2 SCHNAIDERMAN, Boris. "Bakhtin no Brasil: dos estudos de texto ao grande simpósio universal". In Language and Literature Today (atas do XIX Congresso Trienal da Federação Internacional de Línguas e Literatura Modernas). Brasília, Universidade de Brasília: 1996, vol. III. pp. 1386-1388.

${ }^{3}$ BAKHTIN, Mikhail. Problemas da poética de Dostoiévski. Rio de janeiro, Forense Universitária, 1981. Trad. de Paulo Bezerra, p. 158.

4 SCHNAIDERMAN, Boris. Turbilhão e semente - ensaios sobre Dostoiévski e Bakhtin. São Paulo: Livraria Duas Cidades, 1983, p. 90.
} 
a noção de que a poesia lírica ${ }^{5}$ está sempre centrada no eu do poeta parecia algo inabalável.

Num tempo bem mais recente, apareceu o texto de um crítico muito ligado a ele em seus últimos anos de vida, V. Kójinov: "A concepção bakhtiniana sobre poesia lírica", onde se transcrevem algumas anotações inéditas do primeiro. (As concepções deste sobre o épico estão bastante desenvolvidas em outros trabalhos.) Pois bem, depois de considerar a "soberania" do autor como lei imutável da poesia lírica, Bakhtin escreve: “(...) A autoridade do autor e autoridade do coro. A obsessão lírica e essencialmente uma obsessão coral. (...). Eu me ouço no outro, com outros e para outros. (...) $\mathrm{O}$ coro possível - eis uma posição firme e de autoridade. (...). Eu me encontro na voz (...) alheia. (...). Esta voz alheia, ouvida de fora, que organiza a minha vida interior na lírica, e o coro possível (numa atmosfera do silêncio e do vazio absolutos, ela não poderia soar assim; o rompimento individual e completamente solitário do silêncio absoluto tem caráter lúgubre e pecaminoso, degenera em grito, que assusta e incomoda a si mesmo; o rompimento solitário e totalmente arbitrário do silêncio (...) é cinicamente injustificado. Uma voz só pode cantar (...) num ambiente de possível apoio coral." (As reticências reproduzidas do texto russo, e postas por mim entre parênteses, tanto podem referir-se a falhas no texto manuscrito como a cortes efetuados por Kójinov - o que é menos provável.)

Este rascunho de Bakhtin, publicado muitos anos após a morte de Murilo Mendes, parece expressar um sentimento bem semelhante ao espírito da obra do poeta. Algumas expressões, como aquele "caráter lúgubre e pecaminoso" de algo "individual e completamente solitário", parecem fazer eco ao sentimento muriliano de comunhão com todos os homens, àquela sua "tristeza em não poder conversar com esquimós e mongóis"6, e também ao seu horror às ditaduras, à voz que sufoca outras vozes, afirmada por ele com tanta veemência.

Ao contrário do que sucede muitas vezes na obra de Bakhtin, neste rascunho ele não abandona sem qualquer justificativa uma concepção sua e, sem medo de se contradizer, passa a defender uma concepção bem diferente (como acontece quando trata do dialogismo de Tolstói, depois de ter discorrido longamente sobre o monologismo tolstoiano). A noção de coro engloba, na realidade, as suas afirmações sobre a "soberania" do autor na poesia lírica e acrescenta-lhes um nexo com a sua concepção do mundo polifônico.

No comentário a este rascunho, V. Kójinov se volta contra os que procuram aplicar a poesia as noções de "dialogísmo", "polifonia", "voz do outro", elaboradas por Bakhtin em relação a prosa de ficção, sem atentar na

\footnotetext{
${ }^{5}$ KÓJINOV, V. “A concepção bakhtiniana sobre poesia lírica” (em russo). Anuário Dien poésii (Dia da Poesia). Moscou: Editora O Escritor Soviético, 1987, pp. 220-222.

${ }^{6}$ MENDES, Murilo. "Microdefinição do autor", p. 45 (Todos os textos de Murilo Mendes, aqui transcritos baseiam-se em Poesia e prosa completa de Murilo Mendes, Rio de Janeiro: Nova Aguilar, 1994).
} 
existência da "natureza peculiar da prosa literária, que a separa em princípio da obra poética, como tal".

Mas francamente, na prática, contrariando a distinção estabelecida pelo próprio Bakhtin, as categorias por ele estudadas em relação à prosa de ficção funcionam admiravelmente no exame de um texto poético. Por que abafar, no estudioso de poesia, a sensibilidade para certas características de um texto, desenvolvidas por ele a partir de um exame de obras em prosa? Por que deixar de lado a proximidade (aliás, mais do que proximidade, e isto se torna evidente sobretudo numa obra como a de Murilo Mendes) tantas vezes apontada por Pasternak, por exemplo, entre poesia e prosa?

Se o próprio Murilo declara: “(...) dentro de mim discutem um mineiro, um grego, um hebreu, um indiano, um cristão péssimo, relaxado, um socialista amador"7, por que não procurar esta multiplicidade de vozes que aparecem em sua obra?

Certos momentos desta confrontação aparecem particularmente dramáticos.

Creio que o Tristão de Ataíde tem muita razão ao descrever a conversão de Murilo Mendes ao catolicismo como um processo demorado e de muita reflexão. ${ }^{8}$

Suas dúvidas e vacilações, seus sofrimentos morais, são evidentes na obra que precede a sua conversão em 1934. Ele mesmo declarou: “(...) não separo Apolo de Dionísio". 9 Mas, com frequência, isto se manifesta pela ocorrência de vozes em conflito. A própria eliminação de certos poemas parecem indicar isso. Veja-se, como amostra, "Vocação", que é de 1928.

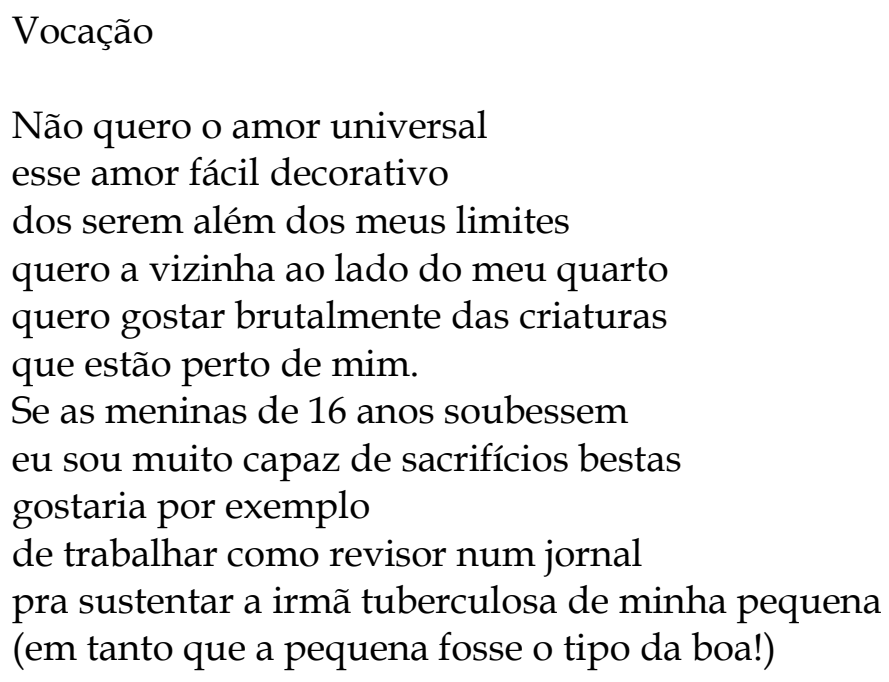

\footnotetext{
7 Id., ib.

8 ATAIDE, Tristão de. "Carta \& Laís Corrêa de Araújo", incluída pela autora em seu livro Poetas modernos do Brasil - Murilo Mendes. Rio de Janeiro: Vozes, 1972, pp. 189-191.

${ }^{9}$ MENDES, Murilo. ld. lb.
} 
Pensemos no porquê da eliminação. Seria por causa do final um tanto popularesco, um tanto poema-piada, em contraste com o tom explosivo e peremptório dos primeiros quatro versos, realmente magníficos? Mas, se ele estivesse sintonizado sem conflito com o tom aí expresso, encontraria com certeza um meio de substituir este final. O mais provável é que ele tenha suprimido o poema justamente por causa destes primeiros versos: a voz do cristão contrito, de espírito ecumênico, universalista, que estava se impondo em seu íntimo, abafou neste caso, segundo parece, o moleque desabusado, voltado para os prazeres terrenos. O garotão dionisíaco, que havia nele, que o acompanhou a vida toda, teve de ceder mais de uma vez ao católico praticante.

Não será nenhuma novidade dizer que sua religiosidade não tinha nada de canônico, os exemplos neste sentido estão aí em profusão em sua obra. Mas com frequência a sua rebeldia entranhada ia muito além disso, e não foi por acaso que Mário de Andrade escreveu: “(...) O catolicismo de MM guarda a seiva de perigosas heresias. " 10 Esta afirmação, tantas vezes atacada, expressa muito bem o susto daquela leitura. O ruim mesmo foi o juízo de valor que Mário de Andrade elaborou a partir do susto que levara.

Com efeito, como são belos os momentos em que Murilo expressa a luta interior, as vozes conflitantes que o dilaceravam! Veja-se, neste sentido, "O poeta na igreja" do livro Poemas (1925 1929):

Entre a tua eternidade e o meu espírito se balança o mundo das formas

e o final desesperado:

seios decotados não me deixam ver a cruz

Me desliguem do mundo das formas!

A voz angustiada sobrepujando a exuberância carnal.

Numa passagem de A idade do serrote (capitulo "Religião"), ocorre o choque com "uma religião afeminada e trouxa" e a afirmação da "virilidade de uma religião que suscita ao longo da história as questões mais altas e dramáticas". E pouco adiante chega a voltar-se contra a florificação da figura "oleográfica" do "meigo nazareno" e afirma a necessidade de uma vivência religiosa que aceite plenamente a "relação profunda entre "erotismo e eroísmo". Assim, exalta \& "épica e a lírica do Novo Testamento", a crítica às "catequistas timbrando mais em acentuar os aspectos restritivos da lei de Moisés". Dialogando, pois, com a concepção de Nietzsche sobre os males causados por nossa formação judaico-cristã, que nos impediu de desenvolver

\footnotetext{
10 ANDRADE, Mário de. "A poesia em pânico". In: O empalhador de Passarinho. Apud Poesia completa e prosa de Murilo Mendes, ob. Cit.
}

170|BORIS SCHNAIDERMAN: Rodapé 
plenamente as possibilidades de um ser humano, Murilo Mendes dá uma visão diferente do problema.

O conflito entre as vozes perpassa toda a sua obra. No capítulo "Dona Caló", igualmente de A idade do serrote, chega a escrever: "Criou-me também um problema de fundo teológico: qual será no outro mundo o lugar dos colós, das colós? Deus amará os chatos?" Assim, ainda em A idade do serrote, no capítulo "Marruzko", fala de "dançarinas de maiô católico, discreto, mas o suficiente para". A própria exuberância, acompanhada de um acento irônico, um tanto distanciado, poderia ser vista igualmente em termos de voz.

E sobretudo aquele diálogo permanente de Murilo com a cultura através do tempo e do espaço, tantas vezes apontado, evidentemente se enquadra nessa perspectiva. Aliás, há uma elaboração requintada a partir desse diálogo, o poeta chega a um diálogo-adesão, a um diálogo convívio, sobre o qual cheguei a escrever num texto em colaboração, a propósito dos Retratos-relâmpagos: “(...) a escrita muriliana cola-se ao objeto, apreende-o antropofagicamente, desdobra-se de acordo com as novas coordenadas traçadas pelo texto que apreende, mas sem deixar jamais de ser Murilo. É algo bem diferente de uma colagem esta adesão total ao texto, mas uma adesão sem perda de personalidade, afirmando-se quando parecia diluir-se, vindo à luz quando parecia acabar." 11 Mas, se tratei ali da diferença em relação à colagem, pode-se também dizer que ele vai muito além do mero pastiche.

O que surge, realmente, é uma voz que adere a outra voz. Temos exemplos disso também em obras anteriores a Retratos-relâmpagos. Assim, o capítulo "Belmiro Braga" de A idade do serrote, sobre aquele poeta mineiro, que foi seu iniciador em poesia, começa com dois decassílabos perfeitos: "Lá vem o volantim Belmiro Braga sorrindo no seu terno xadrez", que poderiam ser o início de um soneto, bem no espírito daquela poesia ora cotidiana e doméstica, ora maliciosa, brejeira, chegando às vezes a sátira, que se desenvolveu no Brasil no início do século, bastante diferente da linha coloquial-irônica, que a crítica detectou no simbolismo.

Ás vezes, no decorrer de sua obra surge um confronto com outras vozes suas contemporâneas. Embora ele não fosse muito afeito à polêmica individualizada, aparece muito clara a voz de protesto, como no caso da bomba atômica, da injustiça social ou da caçoada com certas ideias correntes. O seu livro História do Brasil (1932) caçoa evidentemente das patriotadas da época. Ao mesmo tempo, há neste uma alusão constante a fatos contemporâneos, na leitura que o poeta faz de acontecimentos históricos ou lendários. Por exemplo, O alvo de Caramuru se inicia com a citação de um anúncio de fortificante:

Eu era magro, era assim

Cheguei a ficar quase assim.

${ }^{11}$ SCHNAIDERMAN, Boris e MOREIRA, Elisabel G. "Os relâmpagos de Murilo Mendes". Língua e Literatura. São Paulo: 1976, p. 434.

171|BORIS SCHNAIDERMAN: Rodapé 
No anúncio, estas palavras eram acompanhadas de duas representações de um homem, que aparecia depois vigoroso e sorridente na terceira.

O padre de ferro" tem o final:

Antes deixar como está

Para ver como e que fica!...

Evidentemente, a famosa frase atribuída a Getúlio.

Mas, esse tom galhofeiro, moleque, certamente se tornaria insuportável para o poeta preocupado com o sentido religioso da existência, o que provavelmente explica a exclusão de História do Brasil do seu livro de poemas reunidos, publicado em 1959 pela José Olympio.

Enfim, esta exemplificação de dialogismo em Murilo poderia ir muito longe. Surge, porém, uma dúvida: a maior parte dos elementos aqui apontados não poderiam ser percebidos sem qualquer alusão a Bakhtin? Eu diria que sim, mas sem dúvida a obra bakhtiniana tornou-nos mais sensíveis a eles. Não importa, pois, que isso provenha de seus estudos sobre a prosa literária, e estejamos tratando de poesia. O que ele nos desvenda, como visão de mundo e como visão de texto, vai muito além da distinção que se costuma estabelecer entre prosa e a poesia. Segundo Pasternak, a poesia está no mundo, está nas coisas $^{12}$. Como, pois, excluí-la do grande diálogo universal para o qual Bakhtin aponta? A cor, o som, o palpável dos objetos, todo o mundo que nos rodeia, a prosa, a poesia, tudo isso faz parte do imenso simpósio a que sua obra nos convida.

${ }^{12}$ Cf. PASTERNAK, Boris. "Definição de poesia" e "Poesia". In: CAMPOS , Augusto e Haroldo de. e SCHNAIDERMAN, Boris. Poesia russa moderna - Nova Antologia. São Paulo: Brasiliense, 1985, pp. 136-137. 